\title{
Risk of anaphylaxis in opioid dependent persons: effects of heroin versus substitution substance
}

\author{
Ute Maurer $^{1 *}$, Carola Kager ${ }^{2}$, Christina Fellinger ${ }^{2}$, Dagmara Loader ${ }^{2}$, Augustin Pollesböck ${ }^{3}$, Bernhard Spitzer ${ }^{3}$ \\ and Reinhart Jarisch ${ }^{2}$
}

\begin{abstract}
Background: Across Europe, illicit drug-related mortality has not declined despite ever increasing prevention measures. The cause of these deaths has traditionally been associated with overdose. Previous findings have revealed the appearance of non-lethal opioid concentrations, leading us to investigate a further cause of death. The symptoms of heroin intoxication with asphyxia and/or cardiovascular involvement resemble anaphylaxis, and therefore it has been speculated that such deaths might be caused by an allergic reaction. The study's aims were to investigate levels of allergic mediators in long-term injecting drug users (IDU) compared to healthy controls and to determine if oral opioid substitution therapy (OST) resulted in similar allergic symptoms to those reported by IDU after intravenous (IV) heroin use.
\end{abstract}

Methods: We quantified the concentrations of histamine, diamine oxidase (DAO), tryptase and lipoprotein-associated phospholipase $\mathrm{A}_{2}\left(\mathrm{LpPLA}_{2}\right)$ at baseline and $1 \mathrm{~h}$ after administration of Substitol ${ }^{\oplus}$ retard (482 $\left.\pm 220 \mathrm{mg}\right)$ in 56 patients at a withdrawal centre (Austria) and compared them with healthy controls $(n=103)$. Questionnaires and face-to-face interviews were used to assess allergic symptoms and side effects in IDU. Descriptive statistical analyses of quantitative data were performed by using SPSS.

Results: Baseline histamine, tryptase and LpPLA 2 were significantly elevated in IDU compared to the healthy control group, while DAO decreased. Blood levels showed no significant change after oral substitution uptake. Self-reported allergic symptoms and side effects after IV heroin use were reported in 55 cases (98.2\%), minimal symptoms were documented after OST $(12.5 \%, 7 / 56)$.

Conclusions: This study revealed that baseline histamine concentrations were elevated in chronic IDU, although only relatively small changes in tryptase plasma levels occurred. After IV heroin application the reported allergic symptoms were mostly mild and did not lead to clinically relevant side effects. The substitution substance was clearly better tolerated than IV administered heroin. Elevated levels of allergic mediators such as histamine in IDUs may place them at greater risk of severe or fatal anaphylaxis when exposed to heroin; however, this requires further investigation.

Keywords: Drug Addiction, Anaphylaxis, Histamine, Opioid

\section{Background}

Drug-related mortality is often marked by a lack of demonstrable cause of death. Death due to overdose may be misleading in many cases [1-3]. Several studies have shown a wide range of morphine concentrations, usually non-lethal, in post-mortem samples with coincidental poly drug-use [1,4-6], leading us to investigate a further

\footnotetext{
* Correspondence: ute.maurer@fhwn.ac.at

'Department: Health, Biomedical Science, University of Applied Sciences Wiener Neustadt, Johannes Gutenberg-Strasse 3, 2700 Wiener Neustadt, Austria

Full list of author information is available at the end of the article
}

cause of death. The symptoms of heroin intoxication with asphyxia and/or cardiovascular involvement resemble anaphylaxis, and therefore it has been speculated that such deaths might be caused by an allergic reaction.

Anaphylaxis is a severe, potentially life-threatening allergic reaction affecting multiple organ systems - including the skin, respiratory tract, gastrointestinal tract and central nervous system [7-10]. Common triggers of anaphylaxis include certain foods, insect venom and some medications $[10,11]$. The essential common factor in anaphylaxis, whether by immunological or non- immunological 
mechanisms, is the activation of mast cells and circulating basophils, with the release of preformed vasoactive mediators (such as histamine, mast cell tryptase [MCT] and chymase), newly synthesized cytokines as well as lipidderived mediators [12-16]. These mediators act on target cells and can induce vasodilation, increased permeability, hypotension, bronchospasm and as a result, shock. The symptomatology is variable; there is no obligatory involvement of all organ systems $[17,18]$. Cutaneous manifestations (such as pruritus, flushing, urticaria and angioedema) are by far the most common. But reactions can progress within minutes to respiratory and/or cardiovascular arrest with lethal ending.

The diagnosis of anaphylaxis is based primarily on the clinical picture and history which can be corroborated by serologic laboratory tests. Currently, there is no in vitro test for diagnosing anaphylaxis but the serial measurement of immune mediators, such as histamine, MCT as well as other products of mastocytes or basophils, may be useful for confirming diagnosis and potentially identifying risk [19]. Diagnostic criteria for anaphylaxis were published by a multidisciplinary group of experts [18] who agreed on the lack of information about reliable biomarkers to confirm the clinical impression. Sometimes it is not feasible to obtain samples within the optimum time frame [20]. Moreover, even with early collection of samples, histamine and tryptase may be within normal levels [20]. Therefore they are described as nonspecific markers for anaphylaxis which can be increased in other disease as well [21].

Many opioids are known to stimulate mast cell and basophil degranulation non-specifically $[22,23]$. There are differences in their capacity to cause histamine release along with other mediators as well in variable opioid-dependent effects [24].

In the present study, we investigated allergic symptoms and side effects in IDU after IV heroin injection (self-reported) and after opioid substitution treatment (OST) (observed) within 180 minutes. To determine if long-term IV heroin use result in altered biomarker levels, we analyzed allergic mediators in opioid dependent persons (baseline and after OST) and compared with healthy controls.

\section{Methods}

\section{Study design}

The objectives were addressed by performing quantitative laboratory analysis (immunoassays) and qualitative data analysis (questionnaires, face-to-face interviews).

Blood samples were obtained from opioid dependent persons at a withdrawal centre at Amstetten/Mauer (Austria) who had been undergoing an OST program for 2 weeks. Samples from IDU were taken prior (baseline) and 1 hour after substitution treatment. The first blood sampling was conducted 10 minutes before morning administration. Subsequent sampling proceeded 1 hour after oral intake of substitution substance. Blood analysis served in the determination of baseline allergic biomarkers, such as histamine, diamine oxidase (DAO), tryptase and lipoprotein associated phospholipase $\mathrm{A}_{2}$ $\left(\mathrm{LpPLA}_{2}\right)$. Serum and plasma samples were collected into plain and EDTA vacutainers, using VACUETTE ${ }^{\circ}$ products manufactured by Greiner Bio-One. The tubes were transported in dry ice and centrifuged within $30 \mathrm{mi}-$ nutes after sampling. After centrifugation at $3000 \mathrm{U} / \mathrm{min}$ for 10 minutes, samples were immediately stored at $-20^{\circ} \mathrm{C}$ until analysis. Laboratory analyses were performed at the Floridsdorfer Allergy Centre (FAZ), Vienna (Austria).

Supplementary, the clinical picture of long-term IDU before and after substitution was documented. Therefore face-to-face interviews and questionnaire procedures were used. A structured datasheet was used to record the following factors: demographics, characteristics of allergen/ trigger exposure (kind of opioid, daily dosage, mean duration of regular abuse, etc.), pre-existent allergic conditions and/or mastocytosis as well as self-reported allergic reactions and side-effects shown during former IV drug consumption. After substitution, a structured datasheet was filled in to record treatments, side effects and individual reaction features after 15, 30, 60, and 180 minutes.

\section{Study population}

All participants gave their written informed consent. Approval was also obtained from relevant federal authorities and the ethics committee.

At the withdrawal centre in Amstetten/Mauer, 78 drug addicts (58 male/ 20 female) were tested from a patient population. The key inclusion criteria for OST were a main diagnosis of opiate dependence according to ICD10 [25] as well as suitable venous conditions for blood sampling. Patients' age, sex, or ethnic background were not considered as recruitment criteria for this study. The presence of underlying allergic disease was reported in 22 of 78 cases, such as medication $(n=11)$, grass pollen $(\mathrm{n}=8)$, food $(\mathrm{n}=3)$ and insect sting $(\mathrm{n}=2)$ allergies. Further clinical risk factors for anaphylaxis, comprising comorbidities such as asthma, cardiovascular disease or mastocytosis, were not recognized. In the final analysis, 56 IDU without underlying allergic disease, were included in the study population.

Most subjects had a significant history of regular opioids abuse, ranging from 2 to 25 years. The mean duration of regular heroin abuse was $7 \pm 5.3$ years. All participants at the withdrawal centre in Amstetten/Mauer were treated with Substitol ${ }^{\circ}$ retard. In Austria, Substitol found its role in OST programs to treat heroin addiction as a controlled, slow releasing oral medicine. It is a semisynthetic, highly potent and long acting opioid analgesic 
[26]. Single substance doses varied from 120 to $1000 \mathrm{mg}$ (482 $\pm 220 \mathrm{mg}$ ), depending on type of substance, duration of intake and daily dosage.

For the comparison group volunteers $(n=103)$ were recruited during the same period as the drug addicts between October 2011 and December 2012. 38 male and 65 female persons were included, ages varied from 18 to 61 years (age 31.4 \pm 11.8 ). Subjects with known allergic diseases were excluded.

\section{Laboratory tests}

\section{Histamine}

Histamine, a biogenic amine, is the most important inflammatory mediator released by degranulation of mast cells and basophils during an allergic reaction [27,28]. Many opioids are known to be potent histamine releasers $[29,30]$. Therefore it is of high interest to evaluate baseline histamine concentrations in chronic IDUs. Histamine levels were determined by radioimmunoassay (Immunotec, France) [31]. In brief, blood was collected in a chilled tube containing EDTA and immediately cooled on ice. Samples were centrifuged for 10 minutes at $900 \mathrm{~g} / 4^{\circ} \mathrm{C}$. Acylation buffer and calibrator were then added and immediately vortexed. Results were obtained from the standard curve by interpolation. Normal histamine levels in living subjects are $<0.3 \mathrm{ng} / \mathrm{ml}$ [32].

\section{Diamine oxidase (DAO)}

DAO is a major histamine-degrading enzyme which is found in various tissues, but is primarily active in the intestinal mucosa [33]. DAO activity in serum samples of healthy individuals normally ranged from 10 to $30 \mathrm{U} / \mathrm{ml}$. Lower DAO activity was described as a potential indicator for intestinal mucosa damage in inflammatory and neoplastic disease [34] as well as in cases of fatal anaphylaxis [35]. The activity of DAO was determined by quantitating the reaction product (Sciotec Diagnostics Tulln, Austria) [36]. Radiolabelled putrescine-dihydrochloride was used as a substrate. The result $\Delta^{1}$ pyrroline, containing the radiolabel, was extracted selectively from the matrix by a liquid extraction step. A non-toxic, chlorine-free solvent with high capacity was used for extraction. Finally scintillation fluid was added to the organic phase containing the radiolabelled $\Delta^{1}$-pyrroline and radioactivity was determined in a beta-counter. The signal was directly proportional to the activity of DAO in the sample. Results $<11 \mathrm{U} / \mathrm{ml}$ are judged to be reduced.

\section{Tryptase}

Mast cell tryptase (MCT) is a tetrameric neutral serine protease which is nearly exclusive to mast cells [16,37]. It is more stable, has a longer half-life than histamine and can be detected from a few minutes up to several hours after mast cell degranulation [20,38]. Anti-Tryptase, covalently bound to a solid phase reacted with the tryptase in the serum (Thermo Fisher Scientific, Austria) [39]. After a washing procedure, enzyme labelled antibodies against tryptase was added to form a complex. After incubation, unbound enzyme anti-tryptase was washed away and the bound complex incubated with a developer. After stopping the reaction, the fluorescense of the eluate was measured. The fluorescence was directly proportional to the tryptase concentration of the serum. Normal levels were $<11.4 \mu \mathrm{g} / \mathrm{l}$.

\section{Lipoprotein-associated Phospholipase $A_{2}$}

Lipoprotein-associated phospholipase $\mathrm{A}_{2}\left(\mathrm{LpPLA}_{2}\right)$, a $\mathrm{Ca}_{2}+$ independent phospholipase $\mathrm{A}_{2}$, was identified in human plasma and found to be responsible for hydrolysis and inactivation of platelet-activating factor (PAF) and certain oxidized phospholipids [40]. Although the role of $\mathrm{LpPLA}_{2}$ as a pro- or anti-atherosclerotic enzyme is frequently debated, several studies have shown it to be an independent marker of cardiovascular disease [41,42]. This method (diaDexus, South San Francisco) [43] utilizes monoclonal anti-LpPLA ${ }_{2}$ antibodies directed against $\mathrm{LpPLA}_{2}$ for solid phase immobilization on the micro well plate. Serum samples were added to the plate and after incubation, second monoclonal anti-LpPLA 2 antibody labelled with the enzyme horseradish peroxidase, were added and then incubated with the immobilized antigen. The added substrate, tetramethylbenzidine, followed the immunological reaction. The absorbance of the enzymatic turnover of the substrate was determined by spectrophotometry at $450 \mathrm{~nm}$. It was directly proportional to the present concentration of $\mathrm{LpPLA}_{2}$.

\section{Statistical analysis}

Descriptive statistical analyses of quantitative data were performed by using SPSS, version 20. Comparisons between groups were made by using the Mann-Withney Test. Data was expressed as mean $\pm \mathrm{SD}$. The level of significance was set at $5 \%$.

\section{Results}

At baseline, histamine levels were elevated in IDU (0.50 \pm $0.30 \mathrm{ng} / \mathrm{ml}, 95 \% \mathrm{CI} 0.42-0.58 \mathrm{ng} / \mathrm{ml}$ ) compared to healthy controls $(0.18 \pm 0.15 \mathrm{ng} / \mathrm{ml}, 95 \%$ CI $0.15-0.21 \mathrm{ng} / \mathrm{ml})$ ( $<<0.001$, Mann-Whitney Test), shown in Figure 1. We found increased baseline histamine levels $(>0.3 \mathrm{ng} / \mathrm{ml})$ in 45 of 56 IDUs. Baseline DAO concentrations were decreased in opioid dependent persons $(11.8 \pm 4.9 \mathrm{U} / \mathrm{ml}$, 95\% CI 10.43-13.21U/ml), compared to controls $(15.7 \pm$ 7.7U/ml, 95\% CI 14.19-17.16U/ml) (p <0.05, MannWhitney Test; see Figure 2). In chronic drug abusers, tryptase values varied between 1 and $20 \mu \mathrm{g} / \mathrm{l}(6.0 \pm 4.3 \mu \mathrm{g} / \mathrm{l}$, 95\% CI 4.89-7.18 $\mu \mathrm{g} / \mathrm{l}$; Figure 3 ). In the healthy controls tryptase values varied between 1 and $12.5 \mu \mathrm{g} / \mathrm{l}$ 


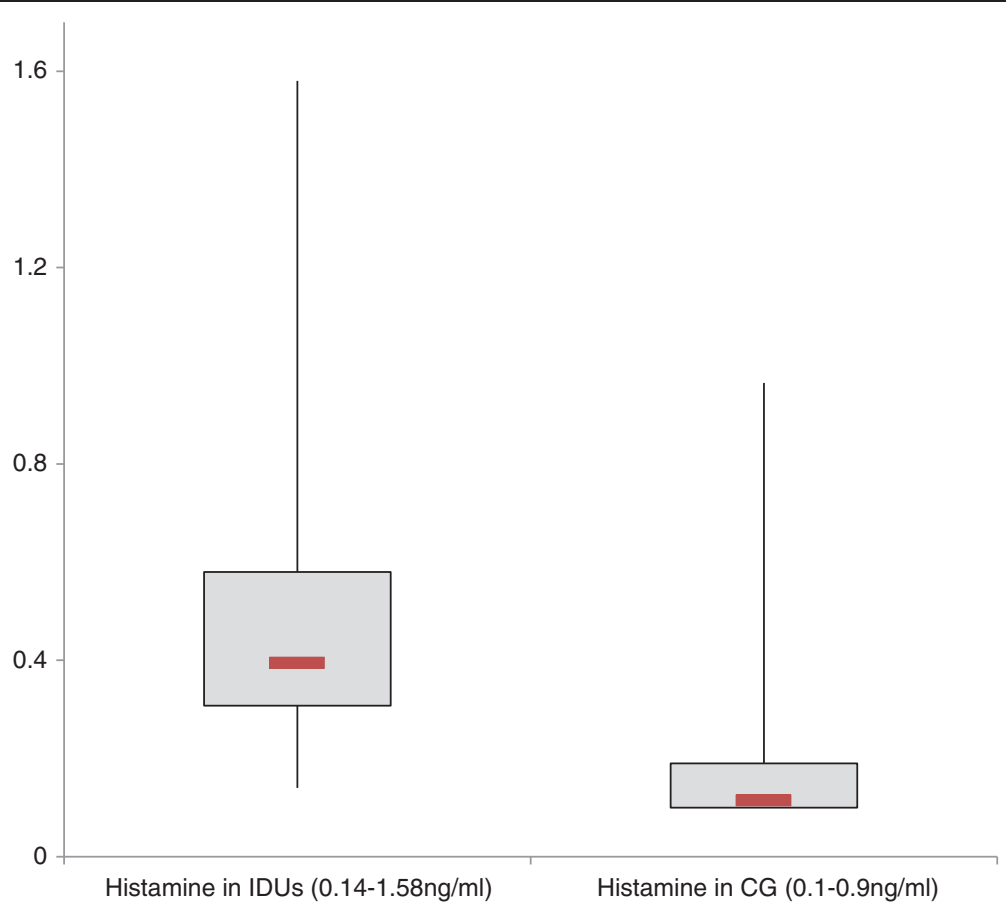

Figure 1 Baseline histamine levels ( $\mathrm{ng} / \mathrm{ml})$ measured in injecting drug users (IDUs) and in comparison group (CG), ( $p<0.001$, Mann-Whitney Test).

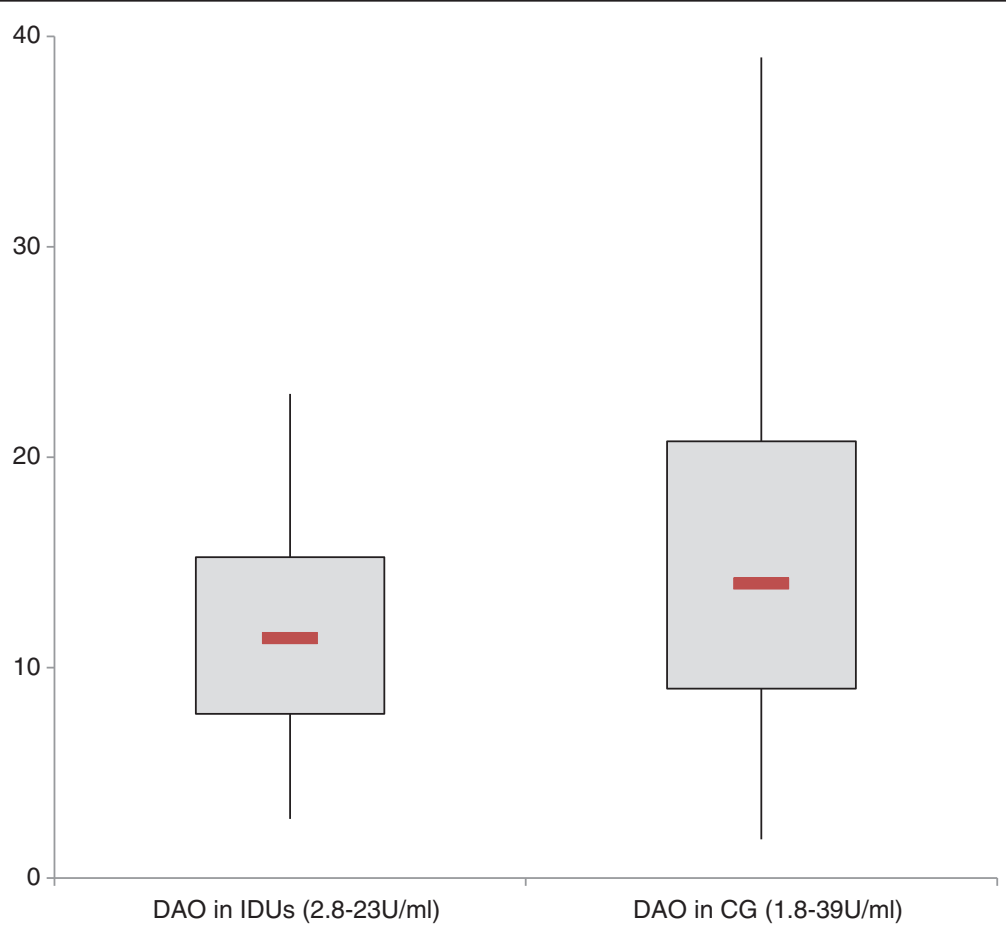

Figure 2 Baseline DAO levels (U/ml) measured in injecting drug users (IDUs) and in comparison group (CG), $(p<0.05$, Mann-Whitney Test). 


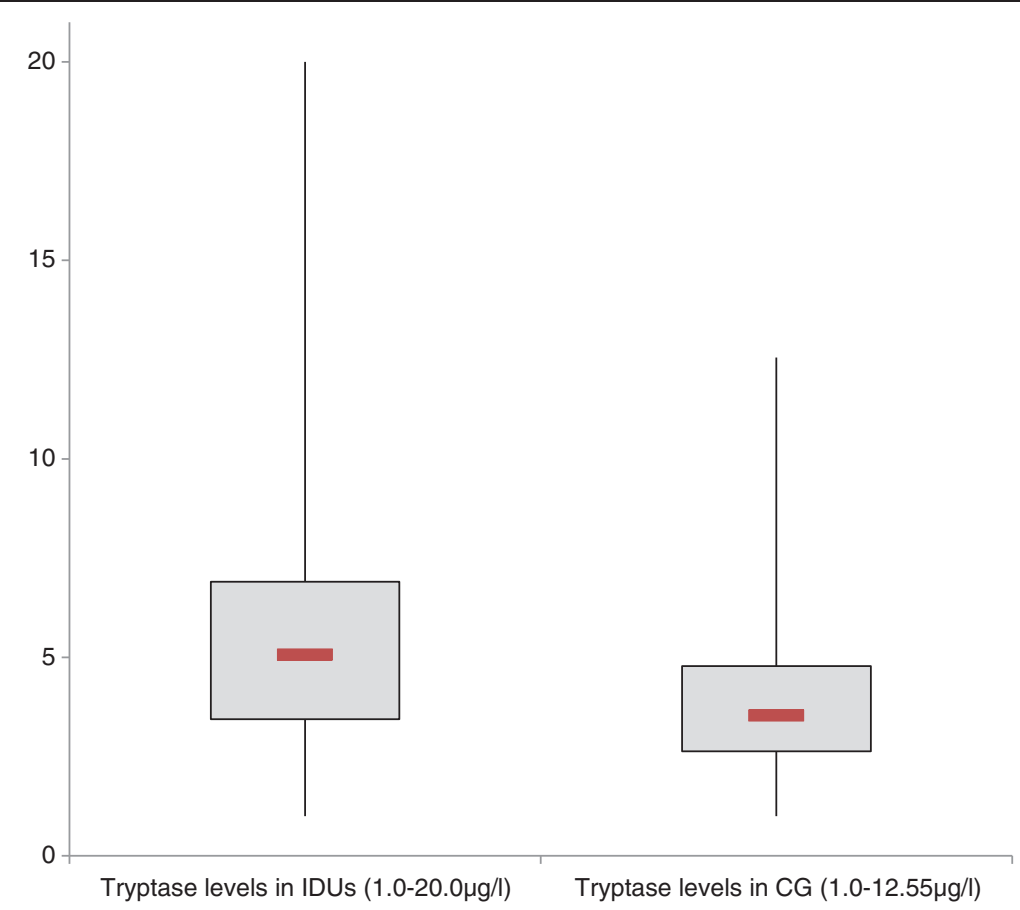

Figure 3 Baseline tryptase levels ( $\mu \mathrm{g} / \mathrm{l})$ measured in injecting drug users (IDUs) and in comparison group (CG), $(\mathrm{p}<0.001$, Mann-Whitney Test).

$(3.9 \pm 1.9 \mu \mathrm{g} / \mathrm{l}, 95 \%$ CI 3.58-4.34 $\mu \mathrm{g} / \mathrm{l} ; \mathrm{p}<0.001$, MannWhitney Test). We found high LpPLA 2 levels in IDUs $(411.9 \pm 125 \mathrm{ng} / \mathrm{ml}, 95 \% \mathrm{CI} 377.27-446.58 \mathrm{ng} / \mathrm{ml})$ versus $333.3 \pm 85.9 \mathrm{ng} / \mathrm{ml}(95 \% \mathrm{CI} 316.76-349.80 \mathrm{ng} / \mathrm{ml})$ in healthy controls ( $<<0.001$, Mann-Whitney Test; Figure 4).
Blood levels of all markers showed no significant change after OST.

After IV heroin, 55 of 56 IDU (98.2\%) self-reported allergic symptoms and side effects. The most common manifestations were cutaneous symptoms which occurred

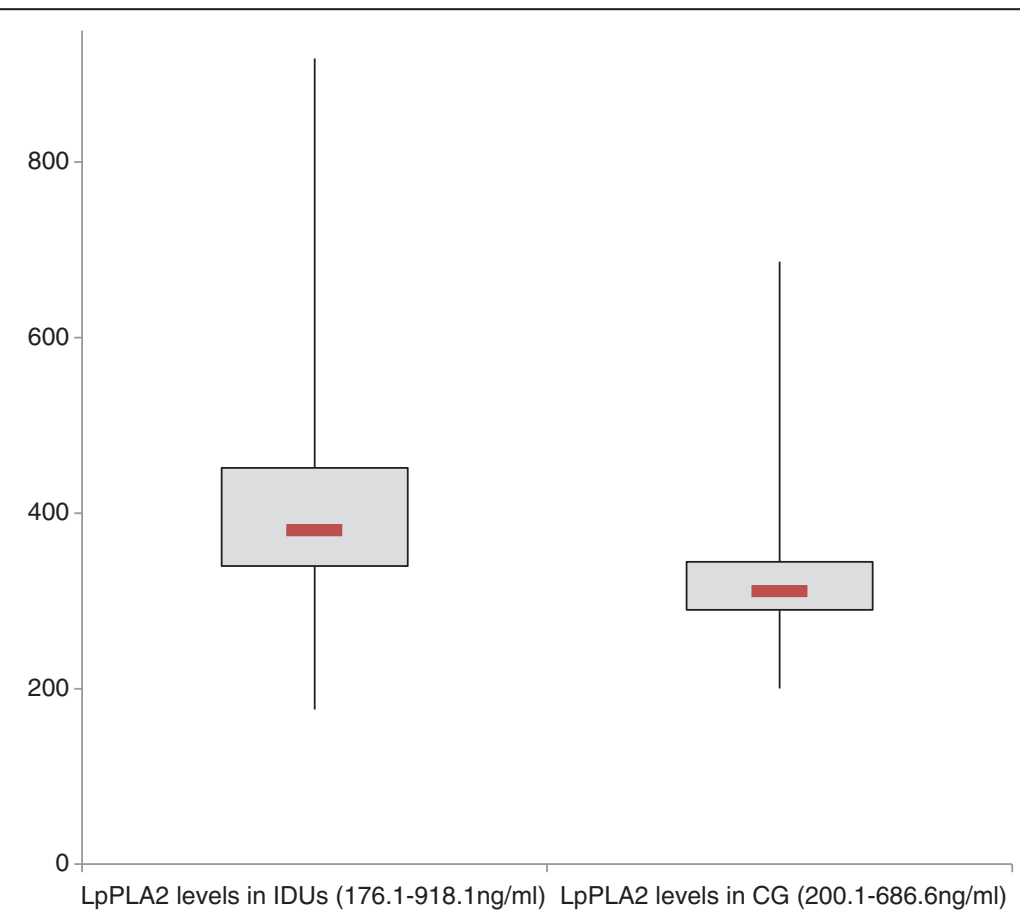

Figure 4 Baseline LpPLA 2 levels ( $\mathrm{ng} / \mathrm{ml}$ ) measured in injecting drug users (IDUs) and in comparison group (CG), ( $p<0.001$, Mann-Whitney Test). 
within the first 15 minutes, including flushing (69.6\%), urticaria (57.1\%), pruritus (55.4\%) and itching of the palms and feet (46.4\%). Respiratory obstruction (dyspnea in 42.9\%) and arrhythmias (51.8\%) were also reported after heroin use.

In contrast, mild symptoms were documented in 7 of 56 cases $(12.5 \%)$ after OST within 180 minutes. All of them showed cutaneous symptoms, including itching of the palms and feet, pruritus and flushing as well as headache and tiredness.

\section{Discussion}

Baseline histamine levels were almost 3-fold higher in chronic IV opioid abusers than in healthy controls. Many opiates are known to induce histamine release by mast cells and basophils causing various effects like vasodilatation, bronchospasm and pruritus $[44,45]$. However, several studies have shown that opioids differ in their capacity to cause histamine release and vary in opioiddependent effects $[22,30,46]$. Divergent study results can be explained with the variable dosage of opioids, its mode and rate of administration, the distribution of histamine receptors in different tissues, the effects of concomitant medications and, the heterogeneity of patient responses to histamine $[24,47,48]$. Histamine is a non-specific marker for allergic reactions with a very short half-life [20]. In the present study it is unlikely that IV heroin is directly responsible for the observed histamine concentrations. It is revealing that elevated histamine may be a consequence of chronic immune activation due to regular heroin use and/ or co-morbidities. In addition to heavy drug use associated with non-immunological symptoms and side effects, immunoglobulin E (IgE) antibody-mediated allergic reactions to opioids which might be rare have to be considered. In such cases skin tests with the suspected drug, drugspecific IgE antibody assays, and flow cytometric activation of basophils with simultaneous analysis of CD63 appearance may help diagnosis [49].

The immune response is further regulated by the balance of both histamine and DAO. Reduced DAO levels were found in IDU (29/56) which might signify low histamine-degrading capacity, allowing a prolonged presence of this vasoactive mediator. Therefore, a reason for elevated histamine in IDU may be competitive inhibition of histamine degradation of DAO by other biogenic amines, alcohol or drugs. Hence, low DAO levels do not seem to be specifically associated with anaphylactic reactions.

Although the mean plasma tryptase levels at baseline were significantly different in IDU versus the comparison group, only 4 of 56 cases tryptase values were above $11.4 \mu \mathrm{g} / \mathrm{l}$ showing marginal elevations $(20,18.8,17.4$ and $17.3 \mu \mathrm{g} / \mathrm{l})$. A relationship between fatal anaphylaxis and elevated tryptase levels was shown in previous studies
[35,50]. Edston et al. [51] found elevated tryptase levels in one third of patients who died after heroin intoxication; however the heroin level was not high enough to explain the fatalities. Rook et al. [52] reported increased tryptase concentrations after IV heroin injection in chronic opioid users, but not after heroin inhalation. This may be explained by the type of entry itself which may affect the type of response to the injected substance.

In the present study $\mathrm{LpPLA}_{2}$ concentrations showed an unexpectedly wide range of variation in both groups. We observed an up-regulation of LpPLA $_{2}$ in IDU. It suggests that increased expression of this enzyme may be a physiological response to inflammatory stimuli. In this context, we have to mention that activated basophils can induce systemic anaphylaxis through the release of the potent platelet-activating factor (PAF) upon stimulation with immune complexes, even though they present less than $1 \%$ of leukocytes in the body [53,54]. Therefore $\mathrm{LpPLA}_{2}$ is attributed to play a pivotal role in anaphylaxis as well as in arteriosclerosis [55].

Our findings clearly indicate that long-term IV heroin application and oral uptake of Substitol retard gave rise to markedly different drug effects. Self-reported allergic symptoms and side-effects after regular IV heroin application were documented in 55 of 56 cases. Most commonly cutaneous manifestations (flushing, urticaria, pruritus) were reported. But in context of the clinical criteria for diagnosing anaphylaxis, skin symptoms alone are not indicating an anaphylactic event. Underlying disease as well as the interference of alcohol or other drugs taken must be examined to be better understood in this context. These findings may be explained by the physiological effects of the injected heroin itself. A report by Haemmig et al. [56], to evaluate the effects of high doses of injected opiates as prescribed in maintenance of IV drug users, showed that in 16 of 39 cases, the study has to be discontinued owing to severe morphine-induced histamine reactions, such as pruritus, urticaria, nausea and flushing. Further studies by Grossmann et al. [57] and Schug et al. [58] described comparable symptoms related to histamine, like itching around the injection site, peripheral vasodilatation and asthmatic attacks after the use of opioids. Though, cases with respiratory involvement in addition with skin features may indicate a moderately severe anaphylactic event.

In contrast minimal symptoms, mostly unspecific ones, were seen after oral substitution medication in 7 of 56 cases. Oral substitution substance was clearly better tolerated than IV administered heroin. These results may indicate a well personalized substitution therapy administered by the medical staff of the withdrawal clinic.

The study is limited by small sample size and lack of adequate information on the general health condition of IDU. Obviously, long-term IV opioid dependent persons 
suffer poorer health due to the complications of drug use characterized by cardiovascular diseases, pulmonary diseases, renal complications, dental problems and gynaecological issues in females. Notwithstanding, hepatitis $B$, hepatitis $C$ and human immunodeficiency virus (HIV) are the predominant infectious diseases in drug addicts which lead to a weak immune system in this population $[59,60]$.

\section{Conclusions}

This effort to open the 'black box' of anaphylaxis is critical to our efforts to understand this condition among IV heroin abusers. This study revealed that baseline histamine concentrations were elevated in chronic IDU, although only relatively small changes in tryptase plasma levels occurred. After IV heroin application the reported allergic symptoms were mostly mild and did not lead to clinically relevant side effects. The substitution substance was clearly better tolerated than IV administered heroin. Elevated levels of allergic mediators such as histamine in IDUs may place them at greater risk of severe or fatal anaphylaxis when exposed to heroin; however, this requires further investigation.

\section{Abbreviations}

IDU: Injecting drug users; OST: Opioid substitution therapy; DAO: Diamine oxidase; LpPLA 2 : Lipoprotein-associated phospholipase $A_{2} ;$ MCT: Mast cell tryptase; IV: intravenous.

\section{Competing interests}

The authors declare that they have no competing interests. Funding was done by the Floridsdorfer Allergy Centre (FAZ), Vienna.

\section{Authors' contributions \\ UM was involved in the research design, carried out the data collection, and drafted the manuscript. CK, CF, DL and AP contributed substantive content and crucial revisions to the manuscript. RJ and BS were involved in the clinical arrangement, the data collection and drafted the manuscript. All authors have reviewed and approved the manuscript submitted.}

\section{Author details}

'Department: Health, Biomedical Science, University of Applied Sciences Wiener Neustadt, Johannes Gutenberg-Strasse 3, 2700 Wiener Neustadt, Austria. ${ }^{2}$ Floridsdorfer Allergy Centre (FAZ), Franz Jonasplatz 8, 1210, Vienna, Austria. ${ }^{3}$ Landesklinikum Mauer, Withdrawal Centre, Hausmeninger Straße 221, 3362 Mauer/Amstetten, Austria.

Received: 25 October 2013 Accepted: 21 February 2014 Published: 27 February 2014

\section{References}

1. Risser D, Honigschnabl S, Stichenwirth M, Pfudl S, Sebald D, Kaff A, Bauer G: Mortality of opiate users in Vienna, Austria. Drug Alcohol Depend 2001, 64(3):251-256.

2. Risser D, Schneider B: Drug-related deaths between 1985 and 1992 examined at the Institute of Forensic Medicine in Vienna, Austria. Addiction 1994, 89(7):851-857.

3. Darke S, Zador D: Fatal heroin 'overdose': a review. Addiction 1996, 91(12):1765-1772.

4. Staub C, Jeanmonod R, Fryc O: Morphine in postmortem blood: its importance for the diagnosis of deaths associated with opiate addiction. Int J Legal Med 1990, 104(1):39-42.
5. Mathers BM, Degenhardt L, Bucello C, Lemon J, Wiessing L, Hickman M: Mortality among people who inject drugs: a systematic review and meta-analysis. Bull World Health Organ 2013, 91(2):102-123.

6. Polettini A, Poloni V, Groppi A, Stramesi C, Vignali C, Politi L, Montagna M: The role of cocaine in heroin-related deaths. Hypothesis on the interaction between heroin and cocaine. Forensic Sci Int 2005, 153(1):23-28.

7. Simons FE: 9. Anaphylaxis. J Allergy Clin Immunol 2008, 121(2 Supp):S402-S407. quiz S420.

8. Simons FE: Anaphylaxis. J Allergy Clin Immunol 2010, 125(2 Suppl 2):S161-S181.

9. Simons FE: World Allergy Organization survey on global availability of essentials for the assessment and management of anaphylaxis by allergy-immunology specialists in health care settings. Ann Allergy Asthma Immunol 2010, 104(5):405-412.

10. Ben-Shoshan M, Clarke AE: Anaphylaxis: past, present and future. Allergy 2011, 66(1):1-14

11. Pumphrey R: Anaphylaxis: can we tell who is at risk of a fatal reaction? Curr Opin Allergy Clin Immunol 2004, 4(4):285-290.

12. Tsai MG, S. G: Mast cells: effector cells of anaphylaxis. In Anaphylaxis and Hypersensitivity Reactions. Edited by Castells MC. New York: Humana Press; 2011:47-68.

13. Lee JK, Vadas P: Anaphylaxis: mechanisms and management. Clin Exp Allergy 2011, 41(7):923-938.

14. Stone SF, Cotterell C, Isbister GK, Holdgate A, Brown SG: Elevated serum cytokines during human anaphylaxis: identification of potential mediators of acute allergic reactions. J Allergy Clin Immunol 2009, 124(4):786-792. e784.

15. Stone KD, Prussin C, Metcalfe DD: IgE, mast cells, basophils, and eosinophils. J Allergy Clin Immunol 2010, 125(2 Suppl 2):S73-S80.

16. Schwartz LB: Effector cells of anaphylaxis: mast cells and basophils. Novartis Found Symp 2004, 257:65-74. discussion 74-69, 98-100, 276-185.

17. Simons FE, Sampson HA: Anaphylaxis epidemic: fact or fiction? J Allergy Clin Immunol 2008, 122(6):1166-1168.

18. Sampson HA, Munoz-Furlong A, Campbell RL, Adkinson NF Jr, Bock SA, Branum A, Brown SG, Camargo CA Jr, Cydulka R, Galli SJ, Gidudu J, Gruchalla RS, Harlor AD Jr, Hepner DL, Lewis LM, Lieberman PL, Metcalfe DD, O'Connor R, Muraro A, Rudman A, Schmitt C, Scherrer D, Simons FE, Thomas S, Wood JP, Decker WW: Second symposium on the definition and management of anaphylaxis: summary report-Second National Institute of Allergy and Infectious Disease/ Food Allergy and Anaphylaxis Network symposium. J Allergy Clin Immunol 2006, 117(2):391-397.

19. Sanz ML, Gamboa PM, Garcia-Figueroa BE, Ferrer M: In vitro Diagnosis of Anaphylaxis. In Anaphylaxis Chemical Immunology and Allergy, Volume 95. Edited by Ring J. Basel: Kager; 2010:125-140.

20. Schwartz LB, Yunginger JW, Miller J, Bokhari R, Dull D: Time course of appearance and disappearance of human mast cell tryptase in the circulation after anaphylaxis. J Clin Invest 1989, 83(5):1551-1555.

21. Schwartz LB: Diagnostic value of tryptase in anaphylaxis and mastocytosis. Immunol Allergy Clin North Am 2006, 26(3):451-463.

22. Baldo BA, Pham NH: Histamine-releasing and allergenic properties of opioid analgesic drugs: resolving the two. Anaesth Intensive Care 2012, 40(2):216-235.

23. Veien M, Szlam F, Holden JT, Yamaguchi K, Denson DD, Levy JH: Mechanisms of nonimmunological histamine and tryptase release from human cutaneous mast cells. Anesthesiology 2000, 92(4):1074-1081.

24. Stellato C, Cirillo R, de Paulis A, Casolaro V, Patella V, Mastronardi P, Mazzarella B, Marone G: Human basophil/mast cell releasability. IX. Heterogeneity of the effects of opioids on mediator release. Anesthesiology 1992, 77(5):932-940.

25. Organization WH: ICD-10, the ICD-10 Classification of Mental and Behavioural Disorders: Diagnostic Criteria for Research. World Health Organization; 1993.

26. Union E: EU Drugs Strategy (2013-2020); 2012.

27. Dale HH, Laidlaw PP: The physiological action of beta-iminazolylethylamine. J Physiol 1910, 41(5):318-344.

28. Parsons ME, Ganellin CR: Histamine and its receptors. Br J Pharmacol 2006, 147(Suppl 1):S127-S135.

29. Di Bello MG, Masini E, loannides C, Ndisang JF, Raspanti S, Bani Sacchi T, Mannaioni PF: Histamine release from rat mast cells induced by the metabolic activation of drugs of abuse into free radicals. Inflamm Res 1998, 47(3):122-130. 
30. Hermens JM, Ebertz JM, Hanifin JM, Hirshman CA: Comparison of histamine release in human skin mast cells induced by morphine, fentanyl, and oxymorphone. Anesthesiology 1985, 62(2):124-129.

31. Immunotech BCC: RIA Histamine, Immunradiometrischer Assay für die quantitative in vitro Bestimmung von Histamin in biologischen Proben. Immunotech SAS:1-18.

32. Jarisch R: Histamin-Intoleranz, Histamin und Seekrankheit. Stuttgart: Thieme Verlag; 2013.

33. Luk GD, Bayless TM, Baylin SB: Diamine oxidase (histaminase): a circulating marker for rat intestinal mucosal maturation and integrity.

J Clin Invest 1980, 66(1):66-70.

34. Raithel M, Ulrich P, Hochberger J, Hahn EG: Measurement of gut diamine oxidase activity. Diamine oxidase as a new biologic marker of colorectal proliferation? Ann N Y Acad Sci 1998, 859:262-266

35. Mayer DE, Krauskopf A, Hemmer W, Moritz K, Jarisch R, Reiter C: Usefulness of post mortem determination of serum tryptase, histamine and diamine oxidase in the diagnosis of fatal anaphylaxis. Forensic Sci Int 2011, 212(1-3):96-101.

36. Diaminoxidase (DAO), Radioextraktionsassay (REA) zur quantitativen Bestimmung der DAO-Aktivität Serum und Plasma. [http://www.sciotec.at/en/ products/diagnostics/]

37. Schwartz LB, Metcalfe DD, Miller JS, Earl H, Sullivan T: Tryptase levels as an indicator of mast-cell activation in systemic anaphylaxis and mastocytosis. N Engl J Med 1987, 316(26):1622-1626.

38. Payne V, Kam PC: Mast cell tryptase: a review of its physiology and clinical significance. Anaesthesia 2004, 59(7):695-703

39. Test Principle ImmunoCAP Tryptase. [http://www.phadia.com/da/Products/ Allergy-testing-products/ImmunoCAP-Assays/ImmunoCAP-Tryptase/]

40. Dada N, Kim NW, Wolfert RL: Lp-PLA2: an emerging biomarker of coronary heart disease. Expert Rev Mol Diagn 2002, 2(1):17-22.

41. Carlquist JF, Muhlestein JB, Anderson JL: Lipoprotein-associated phospholipase A2: a new biomarker for cardiovascular risk assessment and potential therapeutic target. Expert Rev Mol Diagn 2007, 7(5):511-517.

42. Zalewski A, Nelson JJ, Hegg L, Macphee C: Lp-PLA2: a new kid on the block. Clin Chem 2006, 52(9):1645-1650

43. The PLAC Test ELISA Kit. [http://www.plactest.com/international/packageinsert-plac-test-elisa-kit]

44. Hirshman CA, Downes H, Butler S: Relevance of plasma histamine levels to hypotension. Anesthesiology 1982, 57(5):424-426.

45. Fahmy NR, Sunder N, Soter NA: Role of histamine in the hemodynamic and plasma catecholamine responses to morphine. Clin Pharmacol Ther 1983, 33(5):615-620.

46. Barke KE, Hough LB: Opiates, mast cells and histamine release. Life Sci 1993, 53(18):1391-1399.

47. Marone G, Stellato C, Mastronardi P, Mazzarella B: Mechanisms of activation of human mast cells and basophils by general anesthetic drugs. Annales francaises d'anesthesie et de reanimation 1993, 12(2):116-125

48. Levy JH, Brister NW, Shearin A, Ziegler J, Hug CC Jr, Adelson DM, Walker BF: Wheal and flare responses to opioids in humans. Anesthesiology 1989, 70(5):756-760.

49. Leysen J, De Witte L, Sabato V, Faber M, Hagendorens M, Bridts C, De Clerck L, Ebo D: IgE-mediated allergy to pholcodine and cross-reactivity to neuromuscular blocking agents: Lessons from flow cytometry. Cytometry B Clin Cytom 2013, 84(2):65-70.

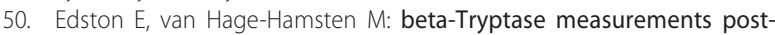
mortem in anaphylactic deaths and in controls. Forensic Sci Int 1998 93(2-3):135-142.

51. Edston E, van Hage-Hamsten M: Anaphylactoid shock-a common cause of death in heroin addicts? Allergy 1997, 52(9):950-954.

52. Rook EJ, Hillebrand MJ, Rosing H, van Ree JM, Beijnen JH: The quantitative analysis of heroin, methadone and their metabolites and the simultaneous detection of cocaine, acetylcodeine and their metabolites in human plasma by high-performance liquid chromatography coupled with tandem mass spectrometry. J Chromatogr B Analyt Technol Biomed Life Sci 2005, 824(1-2):213-221.

53. Karasuyama H, Mukai K, Tsujimura Y, Obata K: Newly discovered roles for basophils: a neglected minority gains new respect. Nat Rev Immunol 2009, 9(1):9-13.

54. Mukai K, Obata K, Tsujimura Y, Karasuyama H: [The roles for basophils in allergy]. Nihon Rinsho 2009, 67(11):2095-2099.
55. Khuseyinova N, Imhof A, Rothenbacher D, Trischler G, Kuelb S, Scharnagl H, Maerz W, Brenner H, Koenig W: Association between Lp-PLA2 and coronary artery disease: focus on its relationship with lipoproteins and markers of inflammation and hemostasis. Atherosclerosis 2005, 182(1):181-188.

56. Haemmig RB, Tschacher W: Effects of high-dose heroin versus morphine in intravenous drug users: a randomised double-blind crossover study. J Psychoactive Drugs 2001, 33(2):105-110.

57. Grossmann M, Abiose A, Tangphao O, Blaschke TF, Hoffman BB: Morphine-induced venodilation in humans. Clin Pharmacol Ther 1996 60(5):554-560

58. Schug SA, Zech D, Grond S: Adverse effects of systemic opioid analgesics. Drug Saf 1992, 7(3):200-213.

59. Nelson PK, Mathers BM, Cowie B, Hagan H, Des Jarlais D, Horyniak D, Degenhardt L: Global epidemiology of hepatitis B and hepatitis $C$ in people who inject drugs: results of systematic reviews. Lancet 2011 378(9791):571-583.

60. Eskild A, Magnus P, Samuelsen SO, Sohlberg C, Kittelsen P: Differences in mortality rates and causes of death between HIV positive and HIV negative intravenous drug users. Int J Epidemiol 1993, 22(2):315-320.

doi:10.1186/1747-597X-9-12

Cite this article as: Maurer et al:: Risk of anaphylaxis in opioid dependent persons: effects of heroin versus substitution substance. Substance Abuse Treatment, Prevention, and Policy 2014 9:12.

\section{Submit your next manuscript to BioMed Central and take full advantage of:}

- Convenient online submission

- Thorough peer review

- No space constraints or color figure charges

- Immediate publication on acceptance

- Inclusion in PubMed, CAS, Scopus and Google Scholar

- Research which is freely available for redistribution

Submit your manuscript at www.biomedcentral.com/submit
C Biomed Central 